\title{
INTERVENCIÓN EN ANSIEDAD A LOS EXÁMENES, OBSESIONES Y COMPULSIONES CONTENDIDAS EN UN TRASTORNO OBSESIVO COMPULSIVO DE LA PERSONALIDAD
}

\section{INTERVENTION IN AN OBSESSIVE-COMPULSIVE PERSONALITY DISORDER WITH EXAM ANXIETY, OBSESSIONS AND COMPULSIONS}

\author{
Lancha, G. y Garrasco, M. A. \\ Servicio de Psicología Aplicada. Facultad de Psicología. UNED \\ Recibido 1-5-03 \\ Aceptado 20-06-03
}

\section{Resumen}

En las líneas sucesivas se detalla el análisis funcional, las hipótesis explicativas y el diseño de la intervención en un sujeto de 32 años con un trastorno obsesivo compulsivo de la personalidad, ansiedad a los exámenes, obsesiones y compulsiones. La intervención se realizó a lo largo de 33 sesiones. Constó de un paquete de técnicas cognitivo-conductuales en las que destacaron la exposición con prevención de respuesta, la reestructuración cognitiva y el entrenamiento en diversas habilidades de afrontamiento. Los resultados evaluados tras la intervención con medidas pretest y postest, así como otros indicadores clínicos, pusieron de manifiesto la remisión de los síntomas y la sustancial mejoría del paciente.

Palabras clave: trastorno obsesivo-compulsivo, ansiedad a los exámenes, intervención.

\begin{abstract}
In this lines we describe the functional analysis, the explanatory hypothesis and the intervention design in a case of a 32 year-old subject with an obsessive-compulsive personality disorder, exam anxiety, obsessions and compulsions. The therapy lasted 33 sessions. It consisted of a groupt of cognitive-behaviourist tecniques. The ones that seemed to be the most successful were the exposure with prevention of response, cognitive restructuration and coping skills training. The results of the intervention assessed with pretest and postest mensurements, as well as other clinical indicatives showed the remission of the symptoms and a significant improvement of the patient.
\end{abstract}

Key Words: Obsessive-Compulsive disorder; exam anxiety and intervention. 


\section{Introducción}

Una situación de evaluación implica para el evaluado cierto nivel de activación que, en principio, facilita el rendimiento y pone en marcha un conjunto de respuestas encaminadas a la resolución de la tarea que se pretende evaluar. Es por ejemplo el caso de los exámenes, una situación en la que muchos estudiantes son evaluados y de cuyos resultados depende, entre otras cosas, su promoción académica o su incorporación al mundo laboral. No obstante, la situación de evaluación, a veces, supone una respuesta excesiva de ansiedad que dificulta el rendimiento y produce una sobrecarga en la memoria de trabajo. Esta sobrecarga interfiere cualquier respuesta cognitiva encaminada a la resolución de la tarea y aumenta la ansiedad percibida. Como se ha recogido en la Ley de YerkesDodson (1908) una activación media o moderada se asocia con un alto rendimiento, en cambio, si la activación es excesiva, el rendimiento empieza a ser cada vez más deficitario. Es por esto y como han estudiado extensamente el grupo de Pekrun et al. (Pekrun, Goetz, Titz y Perry, 2002; Pekrun, 1992; Pekrun y Hofmann, 1996), la ansiedad puede interferir el rendimiento en una prueba de evaluación tal y como es la situación de examen. En el caso que nos ocupa, la ansiedad a los exámenes, como se detallará en las líneas sucesivas, se convierte en una respuesta excesiva de ansiedad condicionada que favorece un malestar psicológico mayor y que desata un trastorno obsesivo compulsivo, al tiempo que se incorpora y forma parte del mismo.

En este caso en concreto, la anticipación de la amenaza del suspenso es la base de un trastorno obsesivo, cuyas obsesiones y compulsiones tienen la función de prevenir o neutralizar un acontecimiento que el paciente considera probable y perjudicial (Carr, 1974; Manzini, 2000 y Botella, 1999). La posible ocurrencia de una amenaza anticipada puede ser percibida como un acontecimiento que genera la transgresión de una norma o que produce un daño del que el sujeto que lo sufre es responsable. Subyace en la base de esta dinámica un elevado miedo a los sentimientos de culpa y un exceso de responsabilidad (Lopatka y Rachman, 1995; Rachman, 1997; Shafran, 1997 SalKovskis et al., 2000). Por tanto, el miedo a la culpa por irresponsabilidad es elevado y produce una actuación obsesiva que se acompaña de una sobrevaloración de las probabilidades de ocurrencia del acontecimiento temido (Manzini, D’Olimpo y Cieri, 2000).

Las creencias y actitudes sobre la posibilidad de control y la omnipotencia para prevenir la desgracia contribuyen a la aparición de esta sintomatología. Como ha señalado Manzini (2000), la sintomatología que el sujeto experimenta será más intensa según los siguientes parámetros: la probabilidad percibida de causar un daño, el elevado control sobre la producción o no del mismo, la inminencia del daño, el significado o la valoración moral y el grado de interferencia en la vida y funcionalidad del sujeto. El paciente valora negativamente la sintomatología obsesiva que siente como egodistónica e intenta evitarla o rechazarla produciendo un efecto contrario al producido: el aumento de la intensidad y el mantenimiento de las obsesiones y de la ansiedad. Este efecto se produce por la exposición breve a estímulos condicionados evocadores de alta ansiedad que, por una parte, dificulta su extinción y habituación y por otra, produce una sensibilización e incubación de la ansiedad (Eysenck, 1979). Las compulsiones tratan de prevenir el cumplimiento de la amenaza con el consiguiente efecto ansiolítico que las mantiene por reforzamiento negativo. En la medida que el sujeto percibe que éstas son insuficientes, aumentan de forma reiterativa y persistente.

El origen del trastorno obsesivo compulsivo es un tema controvertido y aún por concluir. Se apunta un origen multicausal relacionado con variables de predisposición (Cruzado, 1993; Botella,1999; Manzini, 2000; Rachman, 1997) tanto biológicas (ej. disfunción del hemisferio dominante, déficits serotoninérgicos) como psicológicas (ej. acontecimientos estresantes, personalidad, procesamiento de la información) además de variables relacionadas con la historia de aprendizaje y los antecedentes socializadores de la persona que lo padece (Salkovskis, Forrester y Richards, 1998; Manzini, 2000).

La intervención de esta alteración se ha llevado a cabo con diversas técnicas que han ido desde la saciación, la parada de pensamiento, la exposición con prevención de respuesta, la relajación hasta el abordaje de los aspectos de pro- 
cesamiento cognitivo, como la sobrevaloración de los pensamientos y del peligro, la responsabilidad de las consecuencias, la necesidad de control, el perfeccionismo y la fusión pensamiento acción (Rachman, 1993; Cruzado, 1993; McLean et al., 2001). Los estudios de eficacia han señalado la superioridad de las técnicas de exposición con prevención de respuesta acompañada del aprendizaje de habilidades de afrontamiento para el manejo de la ansiedad, frente a terapias de corte más cognitivo (McLean et al., 2001; Krochmalik, Jones y Menzies, 2001; Vallejo, 2001). Sin embargo, las técnicas cognitivas siguen siendo un complemento y alternativa a la exposición que permite abordar otros componentes relacionados con este trastorno y diseñar una intervención diferente cuando la primera no funciona o se muestra insuficiente.

Estas aportaciones teóricas, recogidas en la literatura, han servido para sustentar el análisis e intervención del caso que a continuación exponemos. Se trata de una personalidad obsesivacompulsiva con obsesiones y rituales enmascarados por una respuesta excesiva de ansiedad a los exámenes y del diseño de una intervención psicológica realizada para su abordaje.

\section{Presentación del caso}

\section{Descripción del sujeto y motivo de consulta}

El usuario (en adelante MC) es un varón de 31 años de edad, licenciado universitario y opositor desde los 24 años al Cuerpo Superior del Estado. Su demanda inicial es "eliminar la ansiedad y los bloqueos» que le impiden exponer los temas orales en las situaciones de examen. Esta demanda se extiende posteriormente, al abordaje de la reacción de pérdida de su madre, de los pensamientos obsesivos y rituales y de sus características de personalidad.

\section{Proceso de Evaluación}

\section{- Evaluación inicial: Primera recogida de información}

Las primeras sesiones que se establecieron se dedicaron a la exploración y el despistaje de la demanda y a un primer acercamiento a la sintomatología manifiesta. Para ello se procedió a la utilización de instrumentos de amplio espectro como:

- Entrevista.

- Cuestionario de Síntomas SCL-90-R (Derogatis, 1983. Adaptación al castellano González-Rivera et al., 2002).

- Cuestionario sociobiográfico (versión original del Servicio de Psicología AplicadaSPA).

Los datos aportados por esta primera evaluación permitieron a través del SCL-90-R, un acercamiento inicial a la sintomatología más significativa del usuario. Las puntuaciones centiles, baremadas en población psiquiátrica, fueron superiores a 70 en las escalas de Obsesión-compulsión, Sensibilidad Interpersonal, Depresión, Ansiedad, Hostilidad e Ideación Paranoide. De éstas, destacaron las puntuaciones en las escalas de Obsesión-compulsión y Ansiedad con un centil de 85 y 87 , respectivamente. A través del resto de instrumentos (entrevista y cuestionario sociobiográfico) obtuvimos información sobre los antecedentes y la historia del problema.

\section{Antecedentes Familiares e Historia del problema}

MC es hijo único procedente de una familia de nivel cultural y socioeconómico medio-alto. En su familia, tanto nuclear como extensa, no se han descrito antecedentes psiquiátricos ni psicopatológicos. Su padre es un hombre exigente, que describe como duro y focalizado en el éxito. Su madre falleció de cáncer hace aproximadamente un año y actualmente vive solo con su padre, con quien mantiene una relación que describe como muy buena. MC se educó en un colegio de religiosos, que según él, era muy estricto y exigente. Cuando de pequeño suspendía recibía grandes castigos, y nunca podía hacer lo que le gustaba hasta que no realizara las tareas escolares. Cuando tenía 15 años, MC pegó a su perro y gravó en video la reacción del animal ante el castigo. Este hecho, aparece como una experiencia destacable en su historia personal ya que MC lo considera como una 
prueba de su capacidad para hacer daño y sustenta las obsesiones relacionadas con este tema. En su trayectoria como estudiante a lo largo de la educación primaria, secundaria y universitaria, no aparecen más datos a destacar relacionados con la demanda del problema. Tras finalizar exitosamente los estudios universitarios, decide opositar al Cuerpo Superior del Estado y a lo largo de ocho años prepara oposiciones manteniendo, sin dificultades destacables, un ritmo diario de ocho a nueve horas de estudio y una visita semanal al preparador dónde, entre otras actividades de entrenamiento e instrucción, simula la evaluación propia de esta oposición. Cada vez que se han celebrado los exámenes, MC ha acudido y los ha realizado sin problemas aunque no ha conseguido aprobar. La última vez que opositó, a pesar de que llevaba muy bien preparada la materia, cuando llegó a la prueba oral, experimentó un bloqueo en el transcurso del examen que le impidió continuar y le llevó de nuevo a suspender. $\mathrm{Ni}$ en exámenes anteriores ni en los ensayos con el preparador le ocurrió nada parecido, salvo pequeñas pausas que superaba sin problemas. MC relaciona lo acontecido con la muerte de su madre ocho meses antes del examen y con el hecho de saber que su pareja había conseguido superar el examen de oposición, días antes de presentarse a la prueba. Esto último supuso, por agravio comparativo, cierta presión para sentirse obligado a aprobar. En el momento de llegar a consulta presenta gran malestar psicológico y un miedo elevado a que vuelva a ocurrir el bloqueo en próximas convocatorias.

Además del bloqueo descrito en el examen y el miedo a que se repita, MC relata que experimenta un gran temor a atacar a su novia y el impulso de hacerle daño, clavarle un cuchillo, pegarle o ahogarle mientras ella duerme. Antes, esto le ocurría esporádicamente con su madre e incluso sentía el impulso de agredirle sexualmente. Con su pareja, hace dos años, estos pensamientos e impulsos eran muy frecuentes, disminuyeron espontáneamente y ahora de nuevo reaparecen. Se queja de algunas manías que siempre tiene que realizar para sentirse bien y de alguna preocupación excesiva por la salud y por la posibilidad de contraer un cáncer como el de su madre.

\section{Tratamientos Previos}

MC ha recibido durante tres meses tratamiento psicoanalítico y farmacológico. El primero, decidió abandonarlo ante la ausencia de mejoría, respecto al segundo, toma Lexatín y Sumial cuando se encuentra peor y ante las situaciones de más ansiedad.

\section{- Delimitación y análisis del problema}

\section{Instrumentos de evaluación y resultados}

Para la delimitación y el análisis del problema, se procedió a completar la evaluación inicial con los siguientes instrumentos que se recogen a continuación, añadiendo los resultados más destacados:

- Inventario de depresión de Beck, BDI (Beck et al., 1961). La puntuación del sujeto en este cuestionario fue de 13 , puntuación correspondiente a Depresión leve en población normal.

- Inventario de Situaciones y respuestas de ansiedad, ISRA (Tobal y Cano, 1986). Este instrumento permite evaluar la ansiedad en sus aspectos cognitivos, fisiológicos, conductuales y situacionales. Las puntuaciones del sujeto fueron muy elevadas, pudiéndolas clasificar como Ansiedad Severa en el área cognitiva y fisiológica y Ansiedad Extrema en el área motora.

- Inventario Clínico Multiaxial de Millon (II), MCMI-II (Theodore Millon, 1990). De este cuestionario se obtuvieron puntuaciones, por una parte, sobre los trastornos de la personalidad en relación con los criterios del eje II del DSM III-R (APA 1987) y por otra, los síndromes clínicos del eje I. Respecto a los estilos de personalidad, el sujeto no obtuvo puntuaciones superiores de 75 , lo que muestra que no existen trastornos de personalidad graves, pero podemos destacar puntuaciones superiores a 60 en las escalas: Esquizoide, Fóbica, Dependiente, Histriónica, Narcisista, Compulsiva, Autodestructiva, Esquizotípica y Paranoide. En cuanto a los síndromes clínicos, se encontraron puntuaciones altas en Ansiedad y en Delirios Psicóticos. Al analizar las escalas 
psicométricas del test, se encontró una puntuación alta en Deseabilidad, lo cual lleva a considerar estos resultados con cautela.

- Técnica de la rejilla (Kelly, 1955). Esta técnica, basada en la Psicología de los Constructos Personales de Kelly, permite indagar sobre el sistema de atribución de significados de la realidad que utiliza una persona. Entre los resultados obtenidos en este instrumento, destaca la elección de algunos constructos propios de sujetos con trastornos obsesivos y de personalidad compulsiva tales como responsable, dudoso, rígido o moral (Manzini, 2000; Millon, 1999). Otro de los resultados a señalar son dos dilemas implicativos, resultantes en este caso, de la distancia entre los constructos que el sujeto considera deseables y los que elige para autodefinirse. El primer dilema aparece entre el deseo de ser extravertido y su autodefinición como introvertido: MC se autodefine como introvertido, constructo que delimita con los adjetivos de cabezonería, responsable y culto, valorados positivamente por él. Sin embargo, desearía ser extrovertido, constructo que asocia a los adjetivos irresponsable, inculto y voluble, valorados negativamente. El dilema queda establecido ante el deseo de ser extravertido y la asociación de este constructo con adjetivos percibidos por él como indeseables. El segundo dilema aparece entre su autodefinición como inseguro sexualmente y el deseo de ser seguro, cuando asocia el adjetivo irresponsable, característica valorada negativamente por él, a ser seguro sexualmente.

- Autorregistros: Registros ABC de Ellis; Registros de conductas problemas, antecedentes y consecuentes. Estas medidas permitieron extraer principalmente, las respuestas problemas y el análisis funcional de las mismas, que se comentan a continuación.

\section{Análisis de las respuestas problemas, antecedentes y consecuentes}

Las respuestas problemas que se delimitaron tras la evaluación fueron:
- Ansiedad en sus tres niveles de respuesta. A nivel fisiológico, taquicardias, respiración agitada, molestias en el estómago, sequedad de boca, sudoración, temblores y cefalea tensional; a nivel cognitivo, dificultades de concentración, pensamientos automáticos como «estoy al borde del abismo», «esto está yendo mal»; pensamientos anticipatorios como "me voy a bloquear» "voy a perder el control»; «no voy a poder hacerlo»; «la gente pensará que soy un gilipollas»; "voy a hacer el ridículo»; "voy a suspender el examen»; « a ver si la cago ahora» y rumiaciones sobre necesidad de no equivocarse en el examen, lo que dirán los demás, la posibilidad de contraer una enfermedad o sobre su salud; y a nivel motor, fumar, movimientos repetitivos con alguna parte del cuerpo, movimientos torpes o tomar algún ansiolítico.

- Estado de ánimo deprimido. A nivel emocional y fisiológico, cansancio, anhedonia, tristeza, elevados sentimientos de culpa; a nivel cognitivo, distorsiones (magnificación de los aspectos negativos de su situación actual); atribuciones estables internas y pensamientos desadaptativos (recuerdos sobre la muerte de su madre y comparación con la situación de su pareja; deberías, ej. «debería alegrarme por el aprobado de mi novia»; etiquetas y descalificaciones ej., «soy inseguro», "soy un segundón»). A nivel motor, destaca la ausencia de actividades gratificantes y a nivel motivacional, desesperanza, pérdida de ilusión y excesiva dependencia de los otros.

- Obsesiones: pensamientos intrusivos sobre la posibilidad de bloquearse de nuevo; pensamientos de hacer daño a su pareja; de matarse mientras conduce o de no poder meter la velocidad 5. a; imágenes de sus compañeros con corbata que han superado la oposición; impulsos de agredir a su novia y de gritar en público con la consecuente pérdida de control.

- Rituales motores y de orden, como repasar sistemáticamente dos veces; cantar los temas del examen de oposición el mismo 
día de la semana a la misma hora; cumplir sistemáticamente y en el mismo orden la rutina marcada para el estudio, recorrer las mismas tiendas en un orden concreto.

- Dificultades para conciliar el sueño.

- Conductas excesivas de perfeccionismo: devolver un CD o un libro si la carátula tenía alguna insignificante imperfección; exponer los temas del examen sin olvidar ningún detalle, etc...

- Conductas pasivas y de dependencia: A nivel conductual, cede siempre ante lo que dice su pareja; no se compra aquello que su pareja no quiere o no le gusta; no hace nada que le pueda molestar a ella; justifica ante su padre y su novia todo lo que hace En general, busca continuamente agradar a los demás y hace lo que los otros quieren. A nivel cognitivo, piensa que está viviendo la vida de su pareja y no la propia; piensa que es un "camaleón» y que cambia según con quién esté; se preocupa excesivamente de lo que piensan los demás.

- Intentos para mantener la sensación de control, como por ejemplo, preparar las conversaciones telefónicas antes de llamar.

Otras conductas, consideradas como antecedentes remotos del problema, son además de los rasgos de personalidad obsesiva, las creencias irracionales que se mencionan a continuación:

- Supersticiones: «si alguien me dice algo negativo puede que se cumpla», "si me encuentro a alguien que ha suspendido o con un compañero de su pareja es mala señal», "si sueñan que suspendo puede que se cumpla», creer que es un mal presagio la foto de su calendario.

- Fusión pensamiento-acción moral: «como me divierten las películas y los comics de violencia un día voy a matar a alguien»; "puedo ser un asesino porque me gustan las películas de violencia y porque pegué a un perro y lo grabé» "si las películas de violencia no me producen terror es que no soy normal».

- Otras creencias y/o pensamientos desadaptativos: «dedicarse a las aficiones es perder el tiempo y ser infantil», «soy un inmaduro que depende de su novia y de su padre», «soy un segundón»; «nunca tendré éxito»; «los hombres que lloran son un poco mariquitas», «no deberían gustarme las películas violentas».

Los antecedentes y consecuentes inmediatos se detallan en el análisis funcional de las repuestas problema, recogidos en la tabla 1 . A pesar de la delimitación de las variables en antecedentes, conductas problema y consecuentes, muchas de ellas forman un bucle circular que se retroalimenta mutuamente.

\section{Motivación, recursos del paciente y autoconcepto}

El apaciente estaba muy motivado para solucionar su problema de ansiedad dado su objetivo prioritario de aprobar la oposición. Quería evitar por todos los medios quedarse bloqueado durante los exámenes. No obstante, para los problemas relacionados con las otras obsesiones y con la reacción de duelo por la muerte de su madre, la motivación era escasa y su negativa a intervenir sobre estos temas fue explícita y patente.

En lo que refiere a los recursos del sujeto, MC afrontaba el problema de la ansiedad básicamente recurriendo a la medicación ansiolítica y buscando el apoyo de su pareja y de su padre. El afrontamiento de los problemas obsesivos y del duelo se caracterizó fundamentalmente por la evitación y la negación. Por tanto, los recursos que ponía en marcha ante las conductas problema eran escasos e ineficientes. Sin embargo, MC poseía recursos inutilizados que podrían favorecer su mejoría como sus inquietudes por el cine, la música y otras actividades culturales.

MC se autodescribe como una persona culta, inteligente, brillante, perseverante, imaginativa, con facilidad para agradar a la gente, autocrítico, responsable, perfeccionista y cumplidor, pero considera como defectos el ser una persona tímida, insegura, caprichosa, paranoica, excesivamente responsable, tendente al agobio y a preocuparse por lo que los demás piensan, envidiosa, que reprime emociones, con elevados 


\begin{tabular}{|c|c|c|c|}
\hline $\begin{array}{l}\text { ANTECEDENTES } \\
\text { REMOTOS }\end{array}$ & $\begin{array}{l}\text { ANTECEDENTES } \\
\text { INMEDIATOS }\end{array}$ & RESPUESTA & CONSECUENTES \\
\hline $\begin{array}{l}\text { - Educación severa, centrada en } \\
\text { los valores morales del trabajo, } \\
\text { el esfuerzo y el cumplimiento del } \\
\text { deber } \\
\text { - Elevada exigencia en la etapa } \\
\text { escolar con fuertes castigos. } \\
\text { - Bloqueo en examen oral de opo- } \\
\text { sición } \\
\text { - Su novia aprueba la oposición } \\
\text { - Creencias irracionales } \\
\text { - Rasgos de personalidad }\end{array}$ & $\begin{array}{l}\text { - Estímulos que tuvieron lugar el } \\
\text { día del bloqueo } \\
\text { - Estar con gente que ha aproba- } \\
\text { do } \\
\text { - Dedicar tiempo a ocio } \\
\text { - Interrupciones en su horario de } \\
\text { estudio } \\
\text { - Olvidar detalles en los exáme- } \\
\text { nes } \\
\text { - No cumplir metas sobre aprendi- } \\
\text { zaje de materia de examen } \\
\text { - Pensar que su pareja ha aproba- } \\
\text { do la oposición } \\
\text { - No poder dormir o acostarse tarde } \\
\text { - Anticipación de fracaso } \\
\text { - No realizar rituales } \\
\text { - Situaciones supersticiosas } \\
\text { - Sensibilidad a sensaciones cor- } \\
\text { porales }\end{array}$ & $\begin{array}{l}\text { - Ansiedad } \\
\text { - Taquicardias, respiración agita- } \\
\text { da, molestias estómago, sudora- } \\
\text { ción, sequedad de boca } \\
\text { - Dificultades de concentración, } \\
\text { pensamientos automáticos y } \\
\text { rumiaciones } \\
\text { - Fumar, movimientos repetitivos y } \\
\text { torpes, tomar ansiolíticos } \\
\text { - Obsesiones sobre la posibilidad } \\
\text { de bloquearse } \\
\text { - Obsesión en forma de imágenes } \\
\text { intrusivas de gente que ha apro- } \\
\text { bado la oposición }\end{array}$ & $\begin{array}{l}\text { - Evitar situaciones antecedentes } \\
\text { - Evitar realizar actividades de ocio } \\
\text { - Realizar rituales } \\
\text { - Pensamientos neutralizantes } \\
\text { - Conductas de perfeccionismo y } \\
\text { control } \\
\text { - Dificultades para conciliar el sueño } \\
\text { - Alta sensibilidad a sensaciones } \\
\text { corporales } \\
\text { - Tomar medicación }\end{array}$ \\
\hline $\begin{array}{l}\text { - Con } 15 \text { años, pegar a su perro y } \\
\text { grabar reacción de miedo del } \\
\text { animal } \\
\text { - Disfrutar leyendo historias vio- } \\
\text { lentas o viendo películas gore } \\
\text { - Fusión pensamiento-acción }\end{array}$ & $\begin{array}{l}\text { - Dormir con su pareja } \\
\text { - Mirar a su pareja mientras duer- } \\
\text { me } \\
\text { - Hablar con chicas } \\
\text { - Encontrarse tenso } \\
\text { - Ver una película o leer un cómic } \\
\text { violento } \\
\text { - Fusión pensamiento-acción } \\
\text { moral } \\
\text { - Discutir con alguien }\end{array}$ & $\begin{array}{l}\text { - Obsesiones de hacer daño } \\
\text { - Ansiedad }\end{array}$ & $\begin{array}{l}\text { - Pensamientos neutralizantes } \\
\text { - Dificultades para conciliar el sueño }\end{array}$ \\
\hline $\begin{array}{l}\text { - Rasgos de personalidad relati- } \\
\text { vos al exceso de control }\end{array}$ & $\begin{array}{l}\text { - Estar en situaciones públicas, } \\
\text { como por ejemplo, en un con- } \\
\text { cierto, en un teatro, en un medio } \\
\text { de trasporte público, etc. }\end{array}$ & $\begin{array}{l}\text { - Obsesión de perder el control } \\
\text { (dar un grito, levantarse repenti- } \\
\text { namente, etc.) } \\
\text { - Ansiedad }\end{array}$ & $\begin{array}{l}\text { - Pensamientos neutralizantes } \\
\text { - Evitación de actos públicos }\end{array}$ \\
\hline - Muerte de su madre por cáncer & $\begin{array}{l}\text { - Recuerdos sobre su madre } \\
\text { - Pensamientos sobre su relación } \\
\text { de pareja } \\
\text { - Anticipación de fracaso } \\
\text { - Ausencia de actividades gratifi- } \\
\text { cantes } \\
\text { - Catarro, tos, fumar demasiado o } \\
\text { pensar en posibles dolencias } 0 \\
\text { enfermedades }\end{array}$ & $\begin{array}{l}\text { - Estado de ánimo deprimido } \\
\text { (anhedonia, pensamientos desa- } \\
\text { daptativos, desesperanza) } \\
\text { - Sentimientos de culpa } \\
\text { - Obsesión sobre la posibilidad de } \\
\text { tener un cáncer u otra enferme- } \\
\text { dad } \\
\text { - Ansiedad }\end{array}$ & $\begin{array}{l}\text { - Pensamientos neutralizantes } \\
\text { - Dificultades para conciliar el sueño } \\
\text { - Conductas pasivas y dependien- } \\
\text { tes } \\
\text { - Ausencia de actividades gratifi- } \\
\text { cantes } \\
\text { - Reafirmación de pensamientos } \\
\text { negativos }\end{array}$ \\
\hline - Rasgos de personalidad & $\begin{array}{l}\text { - Conducir un coche } \\
\text { - Volar en avión }\end{array}$ & $\begin{array}{l}\text { - Obsesiones de matarse } 0 \text { de } \\
\text { tener un accidente } \\
\text { - Ansiedad }\end{array}$ & $\begin{array}{l}\text { - Evitar ir en coche o en avión } \\
\text { - Imposibilidad de meter la } 5 .^{\text {a }} \text { mar- } \\
\text { cha cuando conduce } \\
\text { - Dificultades para conciliar el sueño }\end{array}$ \\
\hline $\begin{array}{l}\text { - Rasgos de personalidad relati- } \\
\text { vos al perfeccionismo }\end{array}$ & $\begin{array}{l}\text { - Imperfección } \\
\text { - Cometer un error }\end{array}$ & $\begin{array}{l}\text { - Conductas excesivas de perfec- } \\
\text { cionismo }\end{array}$ & - Disminuir la ansiedad \\
\hline $\begin{array}{l}\text { - Actitudes disfuncionales de } \\
\text { dependencia }\end{array}$ & - Estado de ánimo triste, ansiedad & $\begin{array}{l}\text { - Conductas excesivas de depen- } \\
\text { dencia }\end{array}$ & - Diminuye tristeza y ansiedad \\
\hline
\end{tabular}


sentimientos de culpa y con una fuerte tendencia a controlarlo todo.

\section{- Hipótesis explicativas, delimitación de las variables de cambio}

En el análisis de la historia clínica del paciente y sus antecedentes personales y familiares figuran algunas circunstancias relacionadas con la vulnerabilidad al desarrollo de una alteración ansiosa de carácter obsesiva como una educación severa, centrada en los valores morales del trabajo, el esfuerzo y el cumplimiento del deber (Salkovskis et al., 1998; Manzini, 2000). Concretamente, entre los antecedentes familiares y escolares de MC figuran un control externo excesivo sobre su comportamiento, acentuado por su condición de hijo único y una elevada exigencia para el éxito escolar, habiendo sido fuertemente penalizado cuando éste no se alcanzaba. Posiblemente, esto haya contribuido a la gestación de una personalidad compulsiva caracterizada, por un excesivo sentido de la responsabilidad, elevados sentimientos de culpa por el incumplimiento del deber, un escrupuloso sentido moral, además de alto perfeccionismo, afán de logro y autoexigencias que se traducen en una forma particular de pensar, sentir y actuar. Destacamos como variables añadidas de predisposición, su alta reactividad fisiológica a cualquier situación estresante o aversiva y su enorme sensibilidad a las sensaciones corporales. Partiendo de estas variables de vulnerabilidad como elementos predisponentes a los problemas desarrollados por MC, habría que distinguir entre la adquisición y el mantenimiento de su alteración. En cuanto a la adquisición, aparece en su historia un claro y delimitado acontecimiento estresante, el bloqueo surgido durante el examen oral de la oposición, favorecido seguramente por la ansiedad rasgo propia del sujeto. Esta ansiedad reactiva y mal afrontada produjo un condicionamiento tanto de la situación del examen en todos sus componentes, como del pensamiento intrusivo $\mathrm{y}$ anticipatorio de «me voy a quedar bloqueado» así como el miedo a que esta amenaza, altamente valorada para él, volviese a ocurrir. A su vez, este acontecimiento estresante, unido al malestar arrastrado por la muerte de su madre, deriva en un malestar psicológico que se traduce en respuestas de ansiedad, un aumento y reapari- ción de pensamientos intrusivos, la aparición de compulsiones y un descenso del estado de ánimo.

El malestar ocasionado por esta experiencia estresante, es mantenida por otros elementos de carácter cognitivo y conductual que aparecen en el funcionamiento del sujeto: a) la evitación cognitiva de los pensamientos intrusivos y la evitación conductual de los antecedentes, favorece la sensibilización a los mismos e impide la extinción al tiempo que se ven reforzados negativamente; b) las compulsiones de repetición y orden disminuyen la ansiedad y la percepción de probabilidad de que vuelva a ocurrir la amenaza temida (un posible bloqueo) quedando reforzadas negativamente; c) La ausencia de estrategias adecuadas de afrontamiento, impiden resolver las situaciones con éxito y dificultan una ejecución correcta de la tarea de examen con la consecuente disminución de su percepción de eficacia; d) El conjunto de cogniciones (pensamientos automáticos, distorsiones y creencias irracionales) facilitan e inducen su comportamiento fundamentalmente emocional y motor y lo refuerzan en la medida que éstos confirman los primeros (Ej. voy a bloquearme, me pongo ansioso y me bloqueo, lo sabía, sabía que me iba a bloquear); e) La ausencia de actividades gratificantes se ve reforzada negativamente al disminuir la probabilidad de ocurrencia de la amenaza (tiene más tiempo para estudiar, repasar y asegurarse el aprobado) pero al mismo tiempo, contribuye a la pérdida de reforzadores positivos necesarios para un adecuado estado de ánimo.

El conjunto de estas relaciones se retroalimenta a modo de estructura circular impidiendo la mejoría y perpetuando el problema.

\section{- Diagnóstico}

Según la clasificación multiaxilial del Manual Diagnóstico y Estadístico de los Trastornos Mentales (DSM-IV-TR) podemos clasificar los problemas de nuestro cliente en los cinco ejes correspondientes:

\section{Eje I}

F43.22. Trastorno adaptativo, agudo, mixto con ansiedad y estado de ánimo depresivo [309.28] 
F42.8 Trastorno obsesivo-compulsivo [300.3]

F40.2. Fobia específica, tipo situacional a volar y a conducir [300.29]

Z63.4 Duelo [V62.82]

\section{Eje II}

F60.5 Trastorno obsesivo-compulsivo de la personalidad [301.4]

\section{Eje III}

\section{Ninguno}

\section{Eje IV}

Preparación de una oposición al cuerpo superior del estado durante ocho años

\section{Eje V}

Escala de Evaluación de la Actividad Global, EEAG = 51 (en el momento de la evaluación inicial).

Aunque en el Eje I, MC cumple los criterios diagnósticos para varios trastornos, la significación clínica y la demanda del paciente centraron el análisis del caso y la intervención principalmente en los dos primeros, el trastorno adaptativo y el trastorno obsesivo compulsivo.

\section{Intervención}

\section{- Objetivos Terapéuticos}

Los objetivos acordados con el paciente de acuerdo con su motivación e intereses fueron los siguientes:

1. Aprender estrategias de afrontamiento para el manejo de la ansiedad ante los exámenes.

2. Disminuir las distorsiones y los pensamientos automáticos desadaptativos.

3. Disminuir la sensibilidad a las sensaciones corporales.

4. Disminuir supersticiones y la realización de rituales.

Conseguidos estos objetivos, el paciente accedió a trabajar otras metas relevantes y de significación clínica, a las que antes se había negado:

5. Disminuir las obsesiones de hacer daño a su pareja.

6. Flexibilizar las características propias del trastorno de personalidad obsesivo-compulsivo como son el perfeccionismo, la dedicación excesiva al trabajo con exclusión de actividades de ocio, la necesidad de mantener la sensación de control, la expresión de afecto de manera controlada y la rigidez y obstinación que muestra el sujeto.

7. Disminuir conductas dependientes

8. Disminuir la reacción al duelo

9. Eliminar las fobias a volar y a conducir

\section{- Tratamiento y contrastación de hipótesis}

\section{Relación terapéutica}

La relación terapéutica fue fluida y propició una fuerte alianza que constituyó uno de los pilares de los logros alcanzados y facilitó la intervención y la adherencia al tratamiento.

\section{Técnicas de Intervención}

Las técnicas utilizadas en la intervención fueron principalmente: instrucciones y orientaciones psicoeducativas, biblioterapia, técnicas de autocontrol (autoobservación, autoinstrucciones), técnicas de exposición graduada, exposición con prevención de respuesta (ambas en vivo y en imaginación), uso de matrices para la toma de decisiones, técnicas de administración del tiempo, reforzamiento de los logros, prescripción del síntoma, intención paradójica, técnicas de relajación, ejercicios de respiración, reestructuración cognitiva y algunos ejercicios procedentes de la psicología humanista, como la técnica de las dos sillas, el uso de metáforas y narrativas o la técnica del milagro. A continuación se expone el procedimiento y aplicación de las mismas.

\section{Procedimiento}

La intervención tuvo lugar en 33 sesiones en las que se llevaron a cabo las funciones de evalua- 
ción, tratamiento y seguimiento. Una secuencia más detallada de la evolución de éstas, aparece en la tabla 2. Las sesiones fueron de una hora de duración y de una periodicidad semanal, exceptuando las sesiones de seguimiento que se espaciaron primero, quincenal y después mensualmente.

\begin{tabular}{|c|c|c|c|}
\hline SESIÓN & OBJETIVO & TÉCNICAS & TAREA INTERSESIONES \\
\hline 1 & Evaluación & $\begin{array}{l}\text { Encuadre terapéutico, entrevista de evaluación, cuestionario socio- } \\
\text { biográfico y SCL-90-R }\end{array}$ & Auto-observación (AO) \\
\hline 2 & Evaluación, 1 & $\begin{array}{l}\text { Entrevista de evaluación, BDI, ISRA, psicoeducación (ley Yerkes- } \\
\text { Dowson, explicación modelo de ansiedad de Lazarus, memoria de } \\
\text { trabajo, profecía auto-cumplida) entrenamiento en técnicas de respi- } \\
\text { ración }\end{array}$ & $\begin{array}{l}\text { Auto-registro (AR) tipo } \\
A B C \text {, técnicas de } \\
\text { respiración }\end{array}$ \\
\hline 3 & 1 & $\begin{array}{l}\text { Análisis de periodo intersesiones, planteamiento de objetivos, análisis } \\
\text { de horario y administración óptima del tiempo con días de descanso, } \\
\text { técnicas de respiración y relajación (bibliografía al respecto) }\end{array}$ & $\begin{array}{l}\text { AR, administración del } \\
\text { tiempo, prevención de } \\
\text { respuesta de repaso }\end{array}$ \\
\hline 4 & 1,2 & $\begin{array}{l}\text { Análisis de periodo intersesiones, psicoeducación (TRE, condiciona- } \\
\text { miento clásico, visión túnel), técnicas de respiración y relajación. } \\
\text { Libro de autoayuda "Basta ya!" de Ellis. }\end{array}$ & $\begin{array}{l}\text { AR tipo } A B C \text { y práctica } \\
\text { de relajación }\end{array}$ \\
\hline 5 & $1,2,6$ & $\begin{array}{l}\text { Análisis de periodo intersesiones, psicoeducación (fobias, sensibiliza- } \\
\text { ción vs habituación, modelo explicativo del problema, técnicas de } \\
\text { exposición), refuerzo por haber dejado tareas sin hacer, planteamien- } \\
\text { to de metas realistas y toma de decisiones, relajación condicionada a } \\
\text { la palabra "relax" }\end{array}$ & $\begin{array}{l}\text { AR, relajación } \\
\text { condicionada, exposición a } \\
\text { estímulos día del bloqueo }\end{array}$ \\
\hline 6 & $1,2,6$ & $\begin{array}{l}\text { Análisis de periodo intersesiones, psicoeducación (importancia de } \\
\text { actividades placenteras), reestructuración cognitiva de creencias irra- } \\
\text { cionales y del miedo al fracaso, lista de situaciones ansiógenas, téc- } \\
\text { nica de la rejilla }\end{array}$ & $\begin{array}{l}\text { AR, } 30 \text { min./día de } \\
\text { actividades placenteras, } \\
\text { técnica de respiración } \\
\text { diaria, exposición a ítem } \\
\text { lista }\end{array}$ \\
\hline 7 & 1,2 & $\begin{array}{l}\text { Análisis de periodo intersesiones, refuerzo de logros, reestructuración } \\
\text { cognitiva, entrenamiento en autoinstrucciones de Meichenbaum }\end{array}$ & $\begin{array}{l}\text { AR, examinar y analizar } \\
\text { autoinstrucciones creadas, } \\
\text { exposición a lugar de } \\
\text { examen }\end{array}$ \\
\hline 8 & $1,2,4,7$ & $\begin{array}{l}\text { Análisis de periodo intersesiones, refuerzo de logros, psicoeducación } \\
\text { (conductas dependientes), reestructuración cognitiva de pensamien- } \\
\text { tos automáticos y de supersticiones, análisis y reestructuración de las } \\
\text { atribuciones causales, entrenamiento en autorrefuerzo, planificación } \\
\text { de habilidades de afrontamiento que se utilizarán el día del examen }\end{array}$ & $\begin{array}{l}\text { AR, exposición y puesta en } \\
\text { práctica de habilidades de } \\
\text { afrontamiento }\end{array}$ \\
\hline 9 & $1,2,4$ & $\begin{array}{l}\text { Análisis de periodo intersesiones, refuerzo de logros, reestructuración } \\
\text { cognitiva de creencias irracionales y del miedo al suspenso, consoli- } \\
\text { dación de aprendizaje de habilidades de afrontamiento, exposición en } \\
\text { imaginación a situación de examen y a situaciones supersticiosas uti- } \\
\text { lizando habilidades de afrontamiento }\end{array}$ & $\begin{array}{l}\text { Exposición sin tomar } \\
\text { ansiolíticos, ensayos de } \\
\text { habilidades de } \\
\text { afrontamiento y relajación } \\
\text { antes de dormir }\end{array}$ \\
\hline 10 & 1,5 & $\begin{array}{l}\text { Análisis de periodo intersesiones, refuerzo de logros, relajación, lista } \\
\text { de situaciones ansiógenas, psicoeducación (trastorno obsesivo-com- } \\
\text { pulsivo), exposición en consulta a la obsesión de hacer daño a la tera- } \\
\text { peuta, exposición en imaginación a escenas de hacer daño a su pare- } \\
\text { ja u otra personas, reestructuración cognitiva de creencias asociadas } \\
\text { a obsesiones de hacer daño con análisis de evidencia }\end{array}$ & $\begin{array}{l}\text { Exposición con prevención } \\
\text { de respuesta a obsesiones } \\
\text { de hacer daño }\end{array}$ \\
\hline
\end{tabular}


Tabla 2. Relación de objetivos, técnicas y tareas intersesiones a lo largo del tratamiento (continuación)

\begin{tabular}{|c|c|c|c|}
\hline SESIÓN & OBJETIVO & TÉCNICAS & TAREA INTERSESIONES \\
\hline 11 & 5,8 & $\begin{array}{l}\text { Análisis de periodo intersesiones, refuerzo de logros, evaluación de } \\
\text { creencias asociadas a obsesiones de hacer daño y refuerzo de } \\
\text { logros, psicoeducación (papel de la evitación de estímulos ansióge- } \\
\text { nos), narración de la muerte de su madre, refuerzo y narración de } \\
\text { emociones por haber tirado cosas inútiles de su madre }\end{array}$ & $\begin{array}{l}\text { Exposición a situación de } \\
\text { examen }\end{array}$ \\
\hline 12 & $1,2,6,7$ & $\begin{array}{l}\text { Análisis de periodo intersesiones, refuerzo de logros, reestructuración } \\
\text { cognitiva de creencias sobre el trabajo y de ideas relacionadas con la } \\
\text { sensación de dependencia }\end{array}$ & $\begin{array}{l}\text { Realizar actividades } \\
\text { placenteras } 2 \text { horas/día, } \\
\text { aumentar comunicación con } \\
\text { su pareja, exposición a } \\
\text { cómic violento y a obsesión } \\
\text { de hacer daño a su pareja }\end{array}$ \\
\hline 13 & $2,4,5,6$ & $\begin{array}{l}\text { Análisis de periodo intersesiones, refuerzo de logros, reestructuración } \\
\text { cognitiva de: creencias irracionales, de supersticiones, de ideas rela- } \\
\text { cionadas con la realización de rituales; análisis histórico del exceso } \\
\text { de responsabilidad, reestructuración del sentido del deber y de la cul- } \\
\text { pa por dedicar tiempo a aficiones }\end{array}$ & $\begin{array}{l}\text { Narración de sentimientos, } \\
\text { exposición y supersticiones, } \\
\text { exposición a películas y } \\
\text { cómics violentos }\end{array}$ \\
\hline 14 & $2,6,7$ & $\begin{array}{l}\text { Análisis de periodo intersesiones, refuerzo de logros, reestructuración } \\
\text { cognitiva de creencias asociadas a su inseguridad, técnica del milagro y } \\
\text { reestructuración de su ideal como persona, reestructurar ideas relaciona- } \\
\text { das con las conductas dependientes, refuerzo y potenciación de aficiones }\end{array}$ & $\begin{array}{l}\text { Autocaracterización } \\
\text { (aspectos positivos y } \\
\text { negativos de su forma de } \\
\text { ser) }\end{array}$ \\
\hline 15 & $1,4,5,6$ & $\begin{array}{l}\text { Análisis de periodo intersesiones, refuerzo de logros, aumento de vir- } \\
\text { tudes y de defectos, reestructuración cognitiva de supersticiones y de } \\
\text { la necesidad de mantener el control, pruebas de realidad de las cre- } \\
\text { encias asociadas a las obsesiones de hacer daño, exposición en ima- } \\
\text { ginación a situación de examen y a situaciones supersticiosas utili- } \\
\text { zando habilidades de afrontamiento }\end{array}$ & $\begin{array}{l}\text { Utilizar habilidades de } \\
\text { afrontamiento y expresión } \\
\text { de emociones }\end{array}$ \\
\hline 16 & 1 & $\begin{array}{l}\text { Análisis de periodo intersesiones, refuerzo de logros, psicoeducación } \\
\text { (ansiedad), consolidación de habilidades de afrontamiento aprendi- } \\
\text { das, exposición en imaginación a situación de examen utilizando } \\
\text { habilidades de afrontamiento }\end{array}$ & $\begin{array}{l}\text { Prevención de respuesta de } \\
\text { realizar rituales }\end{array}$ \\
\hline 17 & 1,2 & $\begin{array}{l}\text { Análisis de periodo intersesiones, análisis de los antecedentes remo- } \\
\text { tos del miedo a ser evaluado y reestructuración de ideas relaciona- } \\
\text { das, relajación }\end{array}$ & $\begin{array}{l}\text { Realizar actividades de } \\
\text { placenteras y practicar la } \\
\text { relajación }\end{array}$ \\
\hline 18 & $1,2,3,4$ & $\begin{array}{l}\text { Análisis de periodo intersesiones, refuerzo de logros, prescripción del } \\
\text { síntoma (que se active en sesión) y análisis de pensamientos auto- } \\
\text { máticos asociados, análisis y refuerzo de pensamientos positivos, } \\
\text { reestructuración de la necesidad de realizar rituales y del miedo al } \\
\text { bloqueo, exposición en imaginación a situación de examen y a situa- } \\
\text { ciones supersticiosas utilizando habilidades de afrontamiento }\end{array}$ & $\begin{array}{l}\text { Prevención de respuesta de } \\
\text { realizar rituales, crear unas } \\
\text { autoinstrucciones } \\
\text { específicas para el examen }\end{array}$ \\
\hline 19 & $1,2,4,6$ & $\begin{array}{l}\text { Análisis de periodo intersesiones, análisis de la atribución causal de } \\
\text { los resultados reestructuración de los sentimientos de culpa por } \\
\text { tomarse tiempo libre, inundación a experiencia de fracaso reforzando } \\
\text { su visión más flexible del problema, psicoeducación (rituales) }\end{array}$ & $\begin{array}{l}\text { Prevención de respuesta de } \\
\text { realizar rituales } \\
{ }^{\text {*A partir de esta sesión las }} \\
\text { citas son aleatorias }\end{array}$ \\
\hline 20 & $1,2,6$ & $\begin{array}{l}\text { Análisis de periodo intersesiones, refuerzo de logros, reestructuración } \\
\text { de pensamiento automáticos, reestructuración de actitudes perfeccio- } \\
\text { nistas, relajación }\end{array}$ & $\begin{array}{l}\text { Prescripción del síntoma } \\
\text { (aparentar inseguridad), } \\
\text { exposición a conductas no } \\
\text { perfectas }\end{array}$ \\
\hline
\end{tabular}


Tabla 2. Relación de objetivos, técnicas y tareas intersesiones a lo largo del tratamiento (continuación)

\begin{tabular}{|c|c|c|c|}
\hline SESIÓN & OBJETIVO & TÉCNICAS & TAREA INTERSESIONES \\
\hline 21 & $\begin{array}{l}\text { Evaluación, } \\
1,2,6\end{array}$ & $\begin{array}{l}\text { Análisis de periodo intersesiones, refuerzo de logros, anticipación de } \\
\text { posibles pensamientos automáticos, relativizar examen de oposición, } \\
\text { entrevista de evaluación, matriz de decisiones }\end{array}$ & $\begin{array}{l}\text { Tener un horario flexible a } \\
\text { las circunstancias y con } \\
\text { tiempo de ocio }\end{array}$ \\
\hline 22 & $1,6,7$ & $\begin{array}{l}\text { Análisis de periodo intersesiones, refuerzo de nuevas actitudes más } \\
\text { flexibles y menos dependientes, repaso de habilidades de afronta- } \\
\text { miento, aumentar la percepción de control en la situación de examen }\end{array}$ & \\
\hline 23 & $2,5,6$ & $\begin{array}{l}\text { Análisis de periodo intersesiones, reestructuración de ideas relacio- } \\
\text { nadas con ver una película violenta, refuerzo de conductas más flexi- } \\
\text { ble, psicoeducación (perfeccionismo) }\end{array}$ & $\begin{array}{l}\text { Permitirse cometer errores, } \\
\text { un día de descanso }\end{array}$ \\
\hline 24 & $2,6,7$ & $\begin{array}{l}\text { Análisis de periodo intersesiones, reestructuración de creencias irra- } \\
\text { cionales, técnica de la silla }\end{array}$ & Tomarse un día libre \\
\hline 25 & $3,6,8$ & $\begin{array}{l}\text { Análisis de periodo intersesiones, refuerzo de expresión de emocio- } \\
\text { nes, refuerzo de logros, reestructuración de creencias asociadas al } \\
\text { duelo, exposición a activación fisiológica reestructurando las connota- } \\
\text { ciones negativas asociadas, relajación }\end{array}$ & $\begin{array}{l}\text { Intención paradójica al } \\
\text { dormir, exposición a } \\
\text { activación fisiológica, } \\
\text { ejercicio físico }\end{array}$ \\
\hline 26 & $1,2,3$ & $\begin{array}{l}\text { Análisis de periodo intersesiones, anticipación y afrontamiento de } \\
\text { situación de examen, reestructuración de pensamientos automáticos } \\
\text { relacionados con la activación fisiológica, relativizar situación de exa- } \\
\text { men, uso de metáforas, refuerzo de autoinstrucciones positivas }\end{array}$ & $\begin{array}{l}\text { Ejercicio físico, actividades } \\
\text { placenteras, exposición a } \\
\text { activación fisiológica }\end{array}$ \\
\hline 27 & $1,2,3,6$ & $\begin{array}{l}\text { Análisis de periodo intersesiones, reestructuración de ideas irraciona- } \\
\text { les, exposición a sentimientos de fracaso del año pasado y refuerzo } \\
\text { flexibilidad adquirida, intención paradójica de activación fisiológica }\end{array}$ & Prevención de rituales \\
\hline 28 & $1,2,4$ & $\begin{array}{l}\text { Análisis de periodo intersesiones, exposición en imaginación a situa- } \\
\text { ción de examen y a situaciones supersticiosas utilizando habilidades } \\
\text { de afrontamiento }\end{array}$ & $\begin{array}{l}\text { Uso de habilidades de } \\
\text { afrontamiento y prevención } \\
\text { de rituales }\end{array}$ \\
\hline 29 & 6,8 & $\begin{array}{l}\text { Análisis de periodo intersesiones, refuerzo de logros, expresión de } \\
\text { emociones, uso de metáforas para analizar el cambio, encuadre tera- } \\
\text { péutico }\end{array}$ & $\begin{array}{l}\text { Expresión de emociones, } \\
\text { escribir carta de despedida } \\
\text { a madre }\end{array}$ \\
\hline 30 & 2,6 & $\begin{array}{l}\text { Análisis de periodo intersesiones, refuerzo de logros, reestructuración } \\
\text { de miedos analizando probabilidades de los hechos a los que teme }\end{array}$ & $\begin{array}{l}\text { Ocio, descanso, horario } \\
\text { flexible }\end{array}$ \\
\hline 31 & $1,2,4,6$ & $\begin{array}{l}\text { Análisis de periodo intersesiones, refuerzo de logros, inundación a la } \\
\text { idea de suspender, uso de metáforas, reestructuración actitud perfec- } \\
\text { cionista, exposición en imaginación a situación de examen y a situa- } \\
\text { ciones supersticiosas utilizando habilidades de afrontamiento, respi- } \\
\text { ración abdominal }\end{array}$ & $\begin{array}{l}\text { Respiración abdominal, } \\
\text { actividades placenteras }\end{array}$ \\
\hline 32 & $2,6,9$ & $\begin{array}{l}\text { Análisis de periodo intersesiones, reestructuración de miedos irracio- } \\
\text { nales, expresión de emociones, refuerzo de autocontrol y crecimiento } \\
\text { personal, psicoeducación (fobias) }\end{array}$ & $\begin{array}{l}\text { AR tipo ABC del día de } \\
\text { vuelo }\end{array}$ \\
\hline 33 & 6,9 & $\begin{array}{l}\text { Análisis de periodo intersesiones, reestructuración de ideas irraciona- } \\
\text { les relacionadas con la fobia a volar, reestructuración del miedo a per- } \\
\text { der el control, refuerzo de logros }\end{array}$ & \\
\hline
\end{tabular}

* Los dígitos que aparecen en la columna de objetivos se refieren a la numeración de objetivos señalados en el texto. 
La evaluación inicial del sujeto tuvo lugar en las dos primeras sesiones mediante la entrevista clínica y los instrumentos de evaluación comentados en apartados anteriores. Tras estas sesiones, se plantearon los objetivos terapéuticos relacionados con la demanda principal del paciente: la adquisición de las habilidades necesarias para superar los exámenes de oposición.

Para conseguir dicho objetivo, se comenzó realizando tareas psicoeducativas para que el sujeto entendiera el mecanismo por el que se produjo el bloqueo y cómo se podía evitar. Para ello, se le dio una breve y fácil explicación sobre los mecanismos de ansiedad, la ley de Yerkes-Dowson, los procesos de Condicionamiento Clásico, Condicionamiento Operante y sobre el funcionamiento de la Memoria de Trabajo. A lo largo de todo el proceso se utilizó la auto-observación y los autorregistros, no sólo como medida de evaluación sino también como método para entrenar y facilitar el autocontrol. Dada la personalidad obsesiva unida al miedo a suspender, MC dedicaba todo su tiempo a prepararse el examen sin permitirse realizar actividades placenteras, por ello se trabajó la administración del tiempo incluyendo períodos de descanso y ocio. Los objetivos de esta estrategia fueron aumentar la productividad del sujeto, disminuir sus niveles de estrés, elevar el estado de ánimo y al mismo tiempo, flexibilizar sus actitudes perfeccionistas y disminuir la culpa asociada a lo que para él era una "pérdida de tiempo». La inclusión de tiempo libre y ocio vino unida a la reestructuración de creencias irracionales que estaban asociadas a estas conductas, tal es el caso de la creencia «dedicarse a las aficiones es ser infantil». Por otro lado, para enseñar a MC a controlar su nivel de activación, se le entrenó desde el primer momento, en técnicas de respiración abdominal, ventral y muscular y en técnicas de relajación tanto progresiva como autógena. Otra de las habilidades de afrontamiento que se trabajó fue el uso de autoinstrucciones, según el modelo de Meichenbaum (Meichenbaum, 1987; Meichenbaum y Cameron, 1973). A medida que aumentaba el dominio de estas técnicas por parte del cliente, se reestructuró la percepción sobrevalorada de las consecuencias de la amenaza mediante estimaciones de probabilidad de ocurrencia y anticipando las últimas consecuen- cias. Nuestro objetivo con la utilización de estas técnicas, era conseguir un locus de control interno y desdramatizar las supuestas amenazas temidas. Se reestructuraron las atribuciones externas del paciente respecto a aprobar o suspender, basadas en la realización de rituales o en supersticiones. Se utilizó la exposición con prevención de rituales a situaciones supersticiosas para facilitar la extinción conductual, la habituación fisiológica y la modificación de sus expectativas de amenaza. Todo ello se tradujo en un aumento de su percepción de eficacia. Otro elemento clave, abordado durante todo el proceso, fue disminuir la sensibilidad del sujeto a sus reacciones corporales mediante el uso de la intención paradójica y la exposición a la activación fisiológica, reestructurando las connotaciones negativas y las creencias irracionales asociadas. Puesto que su respuesta de ansiedad estaba facilitada por una serie de pensamientos automáticos, como por ejemplo, «estoy al borde del abismo», "no voy a poder hacerlo» o "voy a suspender el examen», fue fundamental reestructurar estas cogniciones con estrategias procedentes de la Terapia Racional Emotiva de Ellis y con bibliografía de autoayuda, concretamente se le indicó la lectura de Basta ya! (Ellis, 1995). Este proceso de adquisición de habilidades de afrontamiento y reestructuración cognitiva se complementó con las técnicas de exposición ya mencionadas. En primer lugar, se realizó una lista de situaciones ansiógenas y el sujeto se fue exponiendo en vivo a los estímulos evocadores de ansiedad, por ejemplo al lugar de examen. Puesto que la oposición consistía en varios exámenes, antes de cada prueba se realizaba exposición en imaginación utilizando habilidades de afrontamiento. El sujeto realizaba relajación progresiva mientras esperaba a que comenzara la prueba, utilizaba la técnica de respiración como método para concentrarse y empleaba diferentes autoinstrucciones: autoinstrucciones específicas para aplicar antes de comenzar la prueba y durante el estresor; autoinstrucciones de emergencia por si se producían momentos de crisis y autoinstrucciones de reforzamiento al finalizar el examen. Con el objetivo de aumentar la auto-confianza y potenciar las habilidades que se iban adquiriendo, se reforzaban en consulta, los pequeños logros que se iban sucediendo cada semana. 
Conforme la alianza terapéutica se consolidó y la preocupación por el bloqueo ante la situación de examen disminuyó sustancialmente, fue posible trabajar otros aspectos, fuentes de ansiedad. Al igual que con el objetivo anterior, el trabajo con las obsesiones de hacer daño a su pareja comenzó con una explicación de los mecanismos que mantienen el problema y posteriormente, se realizó un trabajo tanto cognitivo como conductual. Por un lado, se reestructuraron las creencias que sustentaban la idea implícita de que era capaz de matar, como por ejemplo, la fusión pensamiento acción-moral ("pensar en algo es tan malo como hacerlo») o creencias como "no deberían gustarme las películas violentas». Por otro lado, se utilizó la exposición con prevención de los pensamientos neutralizantes a diferentes estímulos, es decir, MC provocaba las obsesiones al estar acostado con su pareja, al estar al lado de una mujer o al estar enfrente de la terapeuta sin realizar ninguna compulsión. Según se iba superando el problema el propio sujeto practicaba autoexposiciones que reforzaban las acciones emprendidas. Así por ejemplo, se compraba cómics o veía películas violentas a las que fue progresivamente perdiendo el miedo.

A lo largo de todo el proceso se trabajaron las actitudes y comportamientos propios de su personalidad obsesiva. Por ejemplo, se aumentó el tiempo de ocio; se reflexionó sobre la excesiva conciencia de responsabilidad, simulando un juicio en el que se requería evidencia empírica para atribuir la responsabilidad a un individuo; se expuso al sujeto a errores y a dejar cosas por hacer para disminuir el perfeccionismo; se potenció la expresión de emociones; se reestructuraron las ideas relacionadas con la necesidad de control y se propició la exposición a situaciones imprevistas, tales como, cambiar las citas aleatoriamente de un día para otro, o cambiar planes sin planificación previa.

Otro de los objetivos establecidos fue el disminuir las conductas dependientes. Para ello, se potenció la asertividad y se reestructuraron determinadas ideas erróneas sobre qué es ser dependiente. Se incentivaron las iniciativas tomadas por el mismo y las acciones que emprendía de forma independiente.
El desarrollo de este trabajo transcurrió a lo largo de las 32 sesiones, sin embargo, la reacción al duelo no se pudo trabajar hasta los tres meses aproximados de intervención, a partir de la sesión número 11. Esto se hizo mediante narraciones, actos simbólicos como tirar cosas que pertenecían a su madre, reestructuración de la creencia de que «no sufrió la muerte de su madre porque no lloró» y la expresión de emociones relacionadas.

En las últimas sesiones, sesiones 32 y 33, se trabajaron la fobia a volar utilizando psicoeducación, auto-observación y auto-registro, reestructuración de los miedos irracionales y la exposición en vivo aprovechando un viaje en avión previsto por esas fechas.

Tras haber aprobado el examen y haber conseguido una mejoría notable, se decidió, junto con el cliente, proseguir a través de un seguimiento telefónico con una periodicidad intersesiones de aproximadamente dos meses. Finalmente, transcurridos seis meses y cumplidos los objetivos marcados, se le dio el alta. En estas llamadas telefónicas se evaluaban posibles recaídas y se reforzaba el mantenimiento de logros.

\section{Resultados y seguimiento}

Para evaluar los resultados obtenidos, se tomaron como indicadores los mismos instrumentos que el sujeto completó en la evaluación inicial. Además, se han considerado como indicadores de mejoría, las verbalizaciones de MC que a lo largo de las sesiones han sido punto de referencia.

En relación con los instrumentos psicométricos, los resultados posteriores a la intervención tanto en el Cuestionario de Síntomas (SCL90-R), el Inventario de depresión de Beck (BDI) como en el Inventario de Situaciones y respuestas de ansiedad (ISRA) las puntuaciones disminuyeron significativamente (gráfico 1, 2, y 3). La sintomatología evaluada por el SCL-90-R, disminuyó a valores próximos a cero en muchas de las dimensiones, especialmente en las relativas a depresión y ansiedad. Además del descenso en estas dimensiones, destaca la disminución de la sintomatología relativa a obsesión compulsión, la hostilidad y la ideación paranoide. Coherentemente con la dimensión de depresión 
del SCL-90-R, las puntuaciones procedentes del BDI descendieron en 9 puntos, propias de un estado de ánimo no depresivo. Con igual grado de coherencia resultaron las medidas obtenidas a través del ISRA. La puntuación directa total descendió 181 puntos. La ansiedad cognitiva, fisiológica y motora, bajaron entre 48 y 79 puntos, lo que permitía modificar la clasificación del sujeto desde una ansiedad extrema, correspondiente a los percentiles 95 y 99 a una ansiedad marcada que lo situaba entre los percentiles 30 y 55 .
Las otras medidas, procedentes de los autorregistros, la observación en consulta así como la información aportada por MC, mostraron un descenso de la ansiedad subjetiva percibida ante las situaciones de examen. Así, lo demuestran verbalizaciones como «me he dado cuenta que me he puesto nervioso por una ficción», «todo me lo he creado yo» o «las cosas no van a salir mejor porque sufra». El sujeto adquirió las habilidades de afrontamiento que aplicaba correctamente a cada una de las situaciones indicadas. Se creó un locus de control interno e

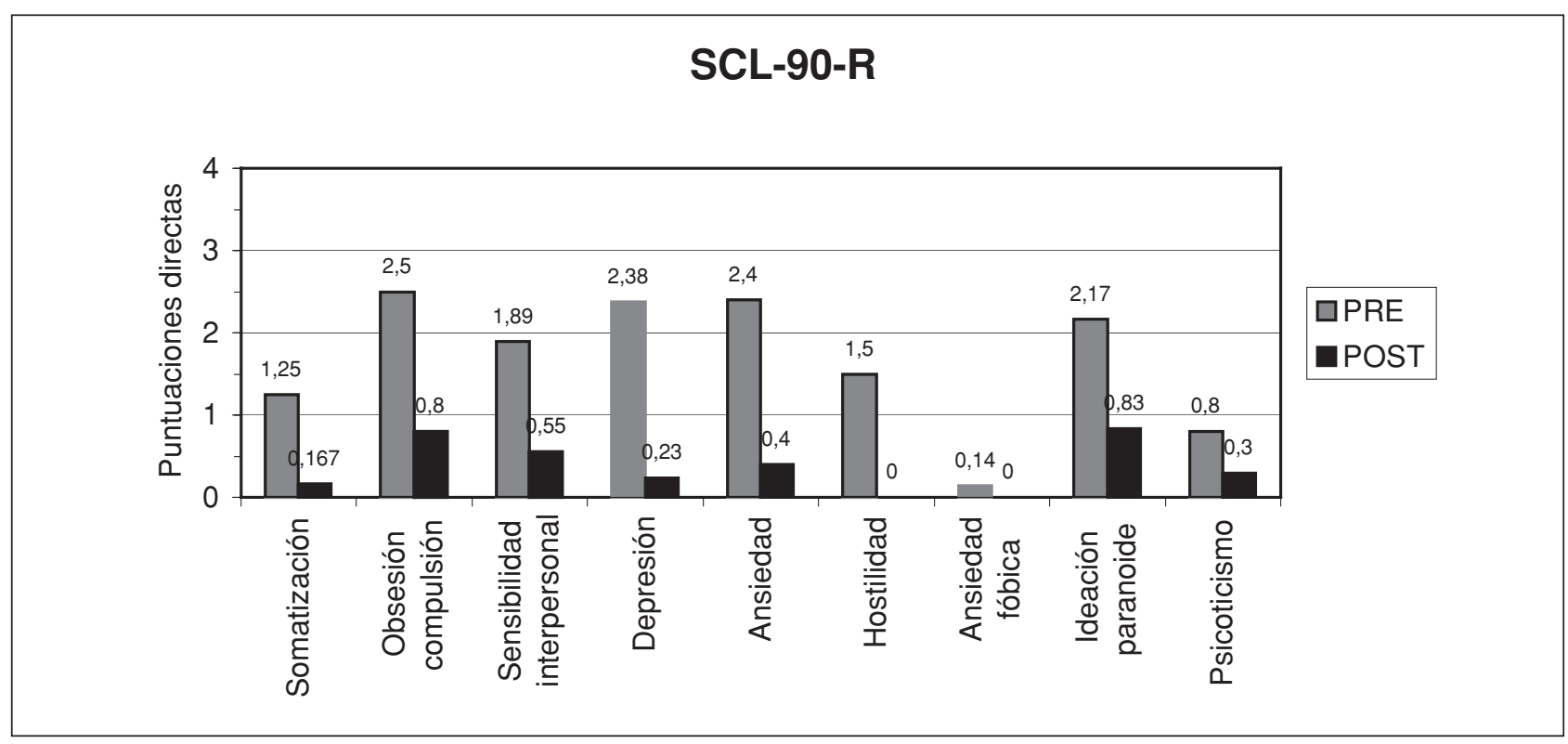

Gráfico 1. Puntuaciones pre-tratamiento y post-tratamiento en el cuestionario SCL-90-R.

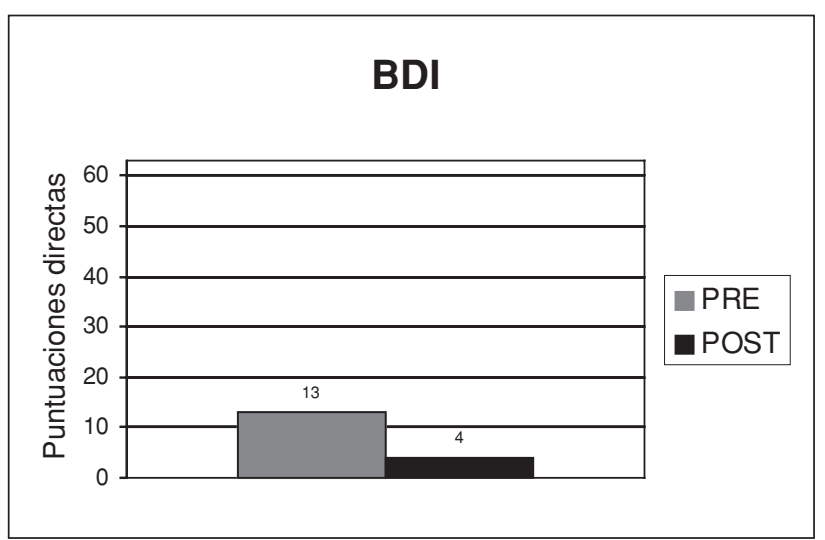

Gráfico 2. Puntuaciones pre-tratamiento y posttratamiento en el cuestionario BDI.

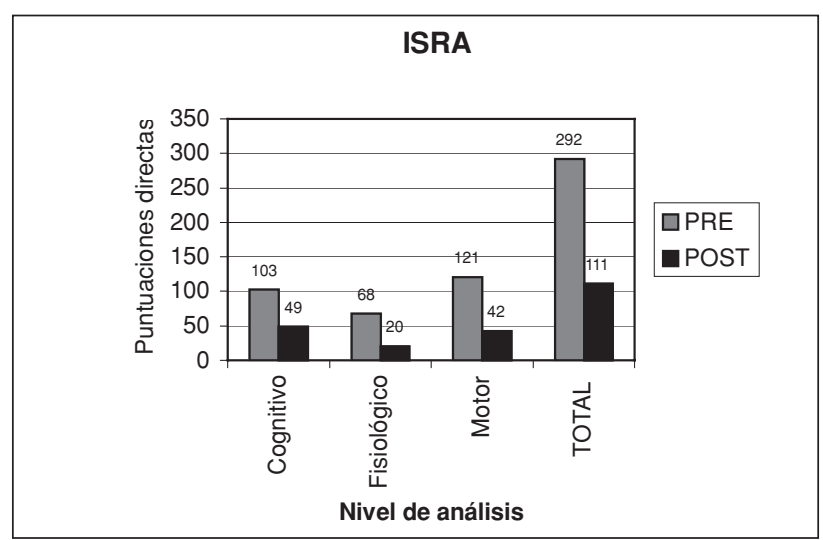

Gráfico 3. Puntuaciones pre-tratamiento y posttratamiento en el cuestionario ISRA. 
independiente de la realización de rituales y disminuyeron sustancialmente, la presencia de creencias irracionales, pensamientos automáticos distorsionados y supersticiones. Una destacada prueba de ello fue, por ejemplo, la asistencia de MC al cine sin repasar y sin sentir culpa por ello, el día anterior al último examen de oposición (examen en el que en la anterior convocatoria se había quedado bloqueado). Por otro lado, la percepción sobrevalorada de las consecuencias de suspender fue más adaptativa. Esto se ve claramente en pensamientos como «no tiene tanta importancia suspender», "ya no me pone nervioso pensar en suspender» o «tanto si suspendo como si apruebo empezaré una etapa nueva». Respecto a la sensibilidad a las sensaciones corporales, disminuyó y MC comenzó a percibirlas como parte de una reacción normal en una situación de ansiedad y consecuentemente desaparecieron los pensamientos automáticos anticipatorios como «esto está yendo mal» o la autoevaluación negativa del rendimiento a pesar de la activación fisiológica percibida. Todos estos avances y logros, en los que su esfuerzo y motivación jugaron un papel fundamental, permitieron a MC superar la oposición al Cuerpo Superior del Estado y quedar entre las 10 primeras mejores notas de su convocatoria.

Las obsesiones de hacer daño se eliminaron por completo, "perdieron significado», según palabras de MC. La idea implícita de ser capaz de hacer daño desapareció, se eliminó la culpa y los prejuicios asociados a ver películas violentas o a leer cómics del mismo género. Prueba de ello fue que, tras la intervención, el sujeto se compraba habitualmente este tipo de cómics, veía películas violentas con su novia y asumió como una afición, ver cine de este género.

Uno de los mayores logros alcanzados fue flexibilizar las características de personalidad obsesiva. Indicadores de ello, fueron la aparición de conductas menos perfeccionistas, su tolerancia a los errores y la desconsideración de nimios detalles cuando empredía una tarea o valoraba un producto o acción. Esto se pudo reflejar en el desempeño de los exámenes, su objetivo evolucionó de pretender hacerlo perfecto a realizarlo de forma más práctica para poder superar la oposición. Otras verbalizaciones que dieron cuenta de su mejoría fueron, «ya no tengo la tabla de los mandamientos, no uso plantillas» o «rigidez, la mínima». Otro aspecto a destacar es la modificación de su sentido excesivo de la responsabilidad, reflejado, por ejemplo, en su mayor dedicación al ocio y al tiempo libre a costa de sus horas de trabajo.

En lo referente a las conductas dependientes, MC comenzó a tomar decisiones de forma autónoma, con independencia de las opiniones de su pareja, su padre o su preparador. Frases como "no voy a hacer lo que diga mi padre o mi novia» $\mathrm{o}$ "ya sé lo que tengo que hacer y no quiero que me lo digan» demuestran la adquisición de una mayor independencia por parte del sujeto. Algunos comportamientos, tales como ser capaz de hablar abiertamente de la pérdida de su madre sin tristeza o culpa, fueron signos de superación de su reacción al duelo. Otros indicadores de mejoría destacables fueron los relacionados con un aumento de la autoconfianza y de la atribución interna de los logros conseguidos. Así lo indican verbalizaciones de MC como, «siento que ahora puedo controlar lo que me ocurre» o "sentirse bien depende de uno mismo».

A nivel general señalamos ideas y sentimientos que fueron aumentando a lo largo de todo el proceso y que de nuevo muestran el grado de mejoría y adaptación del sujeto: «me siento más estable», "ya no tengo obsesiones», «la oposición me ha servido para mejorar a nivel personal», "me siento más maduro», «no adelanto nada preocupándome por las cosas»o «me siento yo mismo».

Por último, los objetivos relacionados con la superación de las fobias, no llegaron a término y no se obtuvieron datos concluyentes, dado que la intervención no se llegó a completar.

\section{Discusión y conclusiones}

La intervención se mostró eficaz no sólo en la medida en que los objetivos se cumplieron sino en la medida que facilitó que el usuario consiguiera superar la oposición y acceder al puesto laboral que pretendía.

Aunque los aspectos metodológicos y de control del presente caso no permiten dilucidar sobre la eficacia de las técnicas, incitan a alguna reflexión al respecto. Del conjunto de técnicas 
aplicadas, la exposición tuvo una enorme eficacia en relación con las obsesiones, especialmente con las de hacer daño, las cuales tuvieron un efecto dominó sobre las demás, que también desaparecieron. Sin embargo, tuvieron un papel fundamental en el progreso terapéutico, la adquisición de habilidades de afrontamiento adecuadas, como por ejemplo, las técnicas de autocontrol, autoinstrucciones y relajación. Las técnicas cognitivas no pueden ser obviadas, especialmente en la intervención sobre aspectos relacionados con la motivación del paciente y sobre la modificación de aspectos propios de la personalidad de MC que potenciaban y favorecían un estado de ansiedad recurrente. Es el caso de sus actitudes rígidas y perfeccionistas, el elevado nivel de autoexigencias, su inminente necesidad de control y la elevada implicación en el trabajo. Por esto, en relación con las técnicas, la exposición mostró su eficacia en relación con la sintomatología más específica de esta alteración, pero no con la ansiedad complementaria que acompañaba y mantenía, en parte, el trastorno. No se puede olvidar que la aplicación inicial de estas técnicas abrieron la puerta y la posibilidad de ahondar en otros aspectos a los que el paciente se resistía trabajar. Es necesario señalar el importante papel que la relación terapéutica tuvo para la mejora de este problema, así como para la motivación del paciente, principalmente en la intervención de otros problemas como la reacción de duelo y las obsesiones de hacer daño. Consideramos pues, de crucial importancia una buena alianza terapéutica para la mejora de los pacientes en general y de éstos en particular.

A pesar de la evidente mejora de MC, aún quedan algunas alteraciones en el eje I, por resolver. Es el caso de la sintomatología hipocondríaca y de las fobias específicas sobre las que el paciente, por motivos laborales, ha decidido no abordar en estos momentos.

El seguimiento ha mostrado la permanencia de los resultados obtenidos aunque sus características de personalidad se mantienen en gran medida, a pesar de haber alcanzado cierta flexibilidad.

\section{Referencias bibliográficas}

Beck, A. T., Ward, C. H., Mendelson, M., Mock, J. y Erbaugh, J. (1961). An Inventory for mesuring depresión. Archives of General Psychiatry, 4, 53-63.
Botella, C., Baños, R. y Gallardo, M. (1999). El trastorno obsesivo compulsivo. Madrid: UNED Fundación Universidad Empresa

Carr, A. T. A. (1974). Compulsive neurosis: a review of literature. Psychological Bulletin, 81, 311-318

Cruzado, J. A. (1993). Tratamiento comportamental del trastorno obsesivo compulsivo. Madrid: Terapia de Conducta y Salud.

Derogatis, L. R. (1983). SCL-90-R Administration, Scoring and Procedures Manual-II. Towson, MD: Clinical Psychometric Research.

Ellis, A. y Bernard, M. E. (eds.) (1990). Aplicaciones clínicas de la terapia racional emotiva. Bilbao, Desclée de Brouwer (trabajo original publicado en 1985)

Ellis, A. y Lange, A. (1995). ;Basta ya!: enfréntese con éxito a las presiones de los demás. Barcelona: Grijalbo Mondadori

Eysenck, H. J. (1979). The conditioning model of neurosis. Behavioural ann Brain Science, 2, 155-199.

Foa, E. B. y Wilson, R. (1992). Venza sus obsesiones. Madrid: Robin.

González-Rivera, J. L., Cuevas, C. Rodríguez, M. y Rodríguez, F. (2002). Manual del cuestionario de 90 sintomas $S C L-90-R$. Madrid: TEA Ediciones.

Kelly, G. A. (1955). The psychology of personal constructs (2 Vols.). Nueva York: Norton. (existe nueva edición en Routledge, Londres, 1991).

Krochmalid, A., Jones, M. K. y Menzies, R. G. (2001). Danger ideation reductin therapy (DIRT) for treatment resistant compulsive washing. Behaviour research and Therapy, 39, 897-912.

Lopatka, C. y Rachman, S. (1995). Perceived responsability and compulsive checking: an experimental análisis. Behaviour Research and Therapy, 33, 673-684.

Manzini, F. (2000). Un modelo cognitivo del trastorno obsesivo-compulsivo. Revista de Psicoterapia, 9, 5-29.

Meichenbaum, D. (1987). Manual de Inoculación de estrés. Barcelona: Martínez Roca.

Meichenbaum, D. y Cameron, R. (1973). Stress Inoculation: A skills training approach to anxiety management. University of Waterloo.

McCarthy, P. R. y Foa, E. B. (1990). Obssessive-compulsive disorder. En M. E. Thase, Edelstein, B.A. y Hersen, M. (Eds.). Handbook of outpatientes treatment of adults. New York: Plenum Press.

McLean, P. D., Whittal, M. L., Thordarson, D. S., Taylor, S., Söchting, I., Koch, W. J., Paterson, R. y Anderson, K. W. (2001). Cognitive versus behavior therapy in the group treatment of obsesivecompulsive disorder. Journal of Consulting and Clinical Psychology, 69, 205-214.

Millon, T. (1999). Trastorno de la personalidad. Más allá del DSM-IV. Madrid: Masson, S.A. 
Paterson, R. y Anderson, K. W. (2001). Cognitive versus behavior therapy in the group treatment of obsessive-compulsive disorder. Journal of Consulting and Clinical Psychology, 69, 205-214.

Pekrun, R., Goetz T., Titz W. y Perry, R. (2002). Academic emotions in students' self-regulated learning and achievement: A program of qualitive and quantitative research. Educational Psychologist, Vol. 37(2), 91-106.

Pekrun, R. y Hofmann, H. (1996). Affective and motivational processes when approaching an exam: contrasting interindividual and intraindividual perspective. Paper presented at the Annual Meeting of the American Educational Research Association. New York.

Pekrun, R. (1992). The impact of emotions on learning and achievement: towards a theory of cognitive/motivational mediators. Applied Psychology: An International Review, 41, 359-376.

Rachman, S. (1993) Obsessions, responsibility and guilt. Behavior Reserch and Therapy, 31, 149-154.

Rachman, S. (1997). A cognitive theory of obsesión. Behariour Research and Therapy, 31, 793-802.
Salkovskis, P. M., Forrester, E. y Richards, C. (1998). Cognitive-behavioural approach to understanding obsessional thinking. British Journal of Psychiatry, 173, 53-63.

Salkovskis, P. M., Shafran, R. y Freeston, M. H. (2000). Multiple pathways to inflated responsibility beliefs in obsessional problems: possible origins and implications for therapy and research. Behaviour Research and Therapy, 40, 2536.

Shafran, R. (1997). The manipulation of responsibility in obsessive-compulsive disorder. British Journal of Clinical Psychology, 36, 397-407.

Tobal, M. y Cano,V. ( 1986). Manual del Inventario de situaciones y respuestas de ansiedad (ISRA). Madrid: TEA.

Vallejo, M. A. (2001). Tratamientos psicológicos eficaces para el trastorno obsesivo compulsivo. Psicothema, vol. 13,3, 419-427.

Yerkes, R. M. y Dodson, J. D. (1908). The relation of strength of stimulus to rapidity of habit formation. United Kingdom: Nature Group. 459-482. 